\title{
Bernard Guenée (1927-2010)
}

\section{Armando Luís de Carvalho Homem}

\section{OpenEdition}

\section{Journals}

\section{Edição electrónica}

URL: http://journals.openedition.org/medievalista/741

DOI: 10.4000/medievalista.741

ISSN: 1646-740X

\section{Editora}

Instituto de Estudos Medievais - FCSH-UNL

\section{Edição impressa}

Data de publição: 1 Janeiro 2012

\section{Refêrencia eletrónica}

Armando Luís de Carvalho Homem, «Bernard Guenée (1927-2010) », Medievalista [Online], 11 | 2012, posto online no dia 21 fevereiro 2014, consultado no dia 06 maio 2019. URL : http:// journals.openedition.org/medievalista/741 ; DOI : 10.4000/medievalista.741 
Título: Bernard Guenée (1927-2010).

Autor(es): Armando Luís de Carvalho Homem

Enquadramento Institucional: Departamento de História e de Estudos Políticos e

Internacionais (FL - UP); Centro de Estudos de População, Economia e Sociedade

(CEPESE)

Contacto: almisch@gmail .com

Fonte: Medievalista [Em linha]. №11, (Janeiro 2012). Dir. José Mattoso. Lisboa: IEM.

Disponível em: http://www2.fcsh.unl.pt/iem/medievalista/

ISSN: 1646-740X

\section{Bernard Guenée (1927-2010)*}

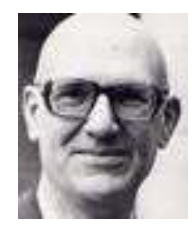

Vítima de AVC, morreu em Paris no dia 25 de Setembro do ano findo o historiador, académico e universitário Bernard-Marie-Albert Guenée. $\mathrm{O}$ funeral realizou-se a 30 do mesmo mês, com celebração litúrgica na igreja de Saint-Germain des Prés - homilia

\footnotetext{
* A $1 .^{\text {a }}$ secção deste trabalho constitui uma reed. adaptada, actualizada e aumentada da 2. ${ }^{\text {a }}$ parte de «Nos 70 anos de Bernard Guenée», Revista da Faculdade de Letras [UP]. História, II sér., XIV (1997): 703711.
} 
pelo aumônier da École Normale Supérieure, P. Jean-Robert Armogathe -, seguida, no mesmo local, do elogio académico, a cargo de Michel Zink - membro do Institut de France / Académie des Inscriptions \& Belles-Lettres (presidente desta no ano em curso) e professor do Collège de France (cadeira de «Littératures de la France Médiévale»); foi sepultado em Rennes, onde nascera. Era casado com Simonne Guenée, diplomada pela École des Chartes, bibliotecária e historiadora das Universidades medievais.

Pessoa de grande simplicidade e de indisfarçável timidez, marcou consideravelmente sucessivas gerações de alunos - foi um assinalável criador de Escola -, leitores ou 'receptores'. Em tempos em que - e de há muito - a 'saída de cena' de um historiador bem pode ser de imediato seguida de desmemória historiográfica, uma (impertinente?) questão me aflora ao espírito: será que no final da presente década ainda leremos Bernard Guenée? Espero viver para ver (e estarei ao tempo em vias de completar 70 anos)...

Bernard-Marie-Albert Guenée nasceu em Rennes (Haute-Bretagne) a 6 de Fevereiro de 1927.

Após estudos liceais na sua cidade-natal, chegou a Paris no Verão de 1944, pouco antes da Libération. Aí cursou os anos finais do Liceu (1944-1946). Seguiu-se a École Normale Supérieure [ENS] (1946-1950), e depois a Sorbonne (Estudos Superiores, 1950 ss.). Também em 1950 concluiu a agrégation (exame de habilitação para o ensino liceal).

Depois do serviço militar e de uma breve passagem pelo ensino secundário, veio a ser bolseiro da Fondation Thiers (1952-1955), e em 1956 iniciou a sua carreira universitária, como Assistente na Sorbonne. Em 1963, aí viria a obter o doctorat d'État, 
com a tese principal Tribunaux et gens de justice dans le bailliage de Senlis à la fin du Moyen Age (vers 1380- vers 1520) ${ }^{1}$ e a tese complementar «Catalogue des gens de justice de Senlis et leurs familles (1380-1550)» ${ }^{2}$; foram seus directeurs de thèse, sucessivamente, Charles-Edmond Perrin (1887-1974) e Robert Boutruche (1904-1975, por jubilação do primeiro).

Entretanto, desde 1958 que ensinava na Universidade de Estrasburgo como maître de conférences, aí atingindo o cume da carreira após o doctorat. Em 1965 regressaria à Sorbonne como professor (sucedendo na cátedra a Yves Renouard [1908-1965]), aí permanecendo (em Paris I Panthéon-Sorbonne a partir de 1970) até à jubilação, em 1995.

Em 1981 foi nomeado directeur d'études da École Pratique des Hautes Études [EPHE] (IV Secção), aí permanecendo também até 1995.

Igualmente em 1981 foi eleito para o Institut de France (Académie des Inscriptions et Belles-Lettres [AIBL]); no quadro desta Academia - a cujo Bureau pertenceu em diversos mandatos, exercendo a Presidência no ano de 1989 -, integrou a Direcção do Journal des Savants.

Três vectores podemos identificar na obra de BG:

1) O primeiro passa pelo que podemos designar de combate por uma nova História política, e inicia-se pelos meados da década de 60, pouco após o doutoramento. Em artigos diversos, publicados nomeadamente na Revue Historique e nos Annales. E.S.C. [e depois reeditados em Politique et Histoire au Moyen Age. Recueil d'articles sur l'histoire politique et l'historiographie médiévale (1956-1981) ${ }^{3}$, BG tem em conta questões como a historiografia francesa sobre o Estado ao longo dos últimos 100 anos (1966), Estado e Nação na França medieval (1967), espaço e Estado (1968) ou as fronteiras medievais francesas (1972).

\footnotetext{
${ }^{1}$ GUENÉE, 1963.

2 Publ. bastante mais tarde, nos Comptes rendus et Mémoires de la Société d'histoire et d'archéologie de Senlis (1979-1980): 20-84; e (1981-1982): 3-96.

${ }^{3}$ GUENÉE, 1981.
} 
Este rumo tem de algum modo o seu culminar em 1971, com o volume L'Occident aux $\mathrm{XIV}^{\mathrm{e}}$ et $\mathrm{XV}^{\mathrm{e}}$ siècles. Les États ${ }^{4}$. Na lógica da estrutura da colecção, a primeira parte compreende uma extensa Bibliografia (742 títulos, agrupados por temas). A segunda parte, Nos connaissances, compreende uma «Introdução» - abordando as noções de Estado e de Ocidente e a periodização - e três livros: «As exigências do espírito», «O poder do Estado» e «Estado e sociedade». Ao longo de um total de 13 capítulos, BG tem em conta questões como «Informação e propaganda», «Ideias e crenças», «Estado e nação», «O príncipe e a sua imagem», «O rei e o tirano», «Os recursos do Estado», «Os fins do Estado» (justiça, finanças, guerra, diplomacia e política económica), «O nascimento do «país»", «O príncipe e o país», «País legal e país real» e «Os servidores do Estado». Finalmente, a terceira parte, Croquis historiographiques, compreende breves abordagens de questões como o Império, as origens da Confederação, «nações e sentimentos nacionais», «Estados e assembleias de estados», «O Parlamento inglês»e «O humanismo cívico». Será quase pleonástico referir a fortuna editorial desta obra, que nos 22 anos subsequentes viria a conhecer um total de quatro edições e uma reimpressão. O Autor não tocou no texto. Mas a dimensão dos sucessivos suplementos bibliográficos (três na 4. ${ }^{a}$ ed., 1991) mostra bem o progresso da investigação nos temas que consubstanciam a obra: na referida $4 .^{\mathrm{a}}$ ed., os títulos triplicam (dos mencionados 742 para 2.2225).

Tal combate por uma "nova" História política como que chega ao seu termo em 1977, com o artigo «Les tendances actuelles de l'Histoire politique du Moyen Age français» ${ }^{5}$. BG coloca-se claramente na perspectiva de somatório do balanço com as perspectivas. Abre com duas constatações de facto:

- «Naguère, l'histoire politique médiévale française s' intéréssait d'abord au chef du corps politique, c'est-à-dire aux rois et aux princes, ensuite aux institutions qui travaillaient à imposer leur volonté, enfin aux événements, révoltes ou batailles, qui menaçaient ou renforçaient leur pouvoir: La lecture des chroniques, l' étude des archives que chaque institution avait laissés suffisaient à

\footnotetext{
${ }^{4}$ GUENÉE, 1971.

${ }^{5}$ In Tendances, perspectives et méthodes de l'Histoire Médiévale, Paris, Bibliothèque Nationale, 1977: 45-70 [ = Actes du $100^{\mathrm{e}}$ Congrès National des Sociétés Savantes (Paris, 1975). Section de philologie et d'histoire jusqu'à 1610, t. I]).
} 
ces ambitions. L' histoire politique était simple. Mais la machine de I' État, quand elle tournait, tournait à vide, sans qu'apparussent les hommes qui la mouvaient ni, à plus forte raison, ceux qui la subissaient. Les historiens qui, à I' exemple des fondateurs des Annales, voulaient "flairer la chair humaine" se détournèrent de cet univers glacé. L'État, les institutions, les évènements tombèrent en disgrâce».

- «(...) Le renversement fondamental est sans doute que les historiens veulent maintenant, dans le corps politique, s'intéresser plus aux membres qu'à la tête, partir non plus du sommet, mais de la base» (pp. 45-46).

E é na decorrência desta dupla observação que BG aponta as prioridades dos anos 70 para a História dos Estados: geografia política (particularmente a problemática dos limites/fronteiras), sociedade política (grupos, tensões, pressões; diversidades regionais; sociedades urbanas; quadros profissionais; quadros familiares; traços de mentalidade e de cultura) e mentalidades políticas (opinião pública e o delicado problema das fontes, com uma chamada de atenção para as «doléances» em assembleias representativas; tensões, violências, crime; propaganda; sentimentos nacionais). E conclui: «(...) la tendance actuelle de I'histoire politique est d'y négliger le sommet pour la base, la tête pour les membres, I' étude des institutions pour celle des sociétés et des mentalités politiques. Ceci implique que, sans négliger le qualificatif, I'histoire politique se tourne autant que faire se peut vers le quantitatif, le statistique et le géographique. L'histoire politique médiévale ne fait donc rien d'autre que ce que fait I'histoire politique contemporaine. (...) L'histoire politique médiévale, telle qu'elle se veut aujourd'hui, est complexe; elle est difficile; mais elle est possible. C'est moins une question de documents qu 'une question d'hommes. Et le seul problème est précisément de savoir si la difficulté ramènera vers I'histoire politique les jeunes historiens que I' ennui en avait détournés» (pp. 69-70).

Os últimos 20 anos encarregaram-se de provar que os «jeunes historiens» tinham mesmo superado o «ennui». Ao mesmo tempo que deixava que a Obra dos discípulos fosse falando por si própria, BG ia tendo uma presença aparentemente mais discreta neste domínio. Centrado em boa parte na época de Carlos VI (1380-1422), privilegiando agora as mentalidades políticas - domínio que na sua Obra tivera a primeira grande 
manifestação no volume Les entrées royales françaises de 1328 à $1515^{6}$ [em col. com Françoise Lehoux], foi abordando questões como a idade dos homens da Igreja e do Estado, bem como de alguns criadores culturais: «L'âge des personnes authentiques. Ceux qui comptent dans la société médiévale sont-ils jeunes ou vieux?» ${ }^{7}$; o Rei e os seus: «Le roi, ses parents et son royaume en France au $\mathrm{XIV}^{\mathrm{e}}$ siècle» ${ }^{8}$; o juramento: «Non perjurabis. Serment et parjure en France sous Charles VI» ${ }^{9}$; as procissões especiais parisienses como instrumento de propaganda (cf. o ponto 1. desta nótula) ou a devoção do monarca (tema do último Seminário que regeu na EPHE).

2) Teremos depois uma atenção nítida à Historiografia da Idade Média ocidental domínio que vinha sendo preparado desde o início da década de 70, em artigos versando, por exemplo, os géneros históricos medievais (histórias, anais, crónicas) [1973], a cultura histórica dos nobres [1976], tempo da história e tempo da memória [1976-77], genealogias, história e política [1978], Marsílio de Pádua e a história [1979], as normas da crítica histórica na Idade Média [1980] ou o próprio conceito de Historiografia medieval [1977], artigos estes em parte reeditados no mencionado volume Politique et histoire ${ }^{10}{ }$. Na mesma linha de ideias se compreende a direcção do volume Le métier d'historien au Moyen Âge. Études sur l'historiographie médiévale ${ }^{11}$, onde colabora com o texto «L'historien par les mots» (pp. 1-17).

Este domínio culmina de certa maneira em 1980, com Histoire et culture historique dans l'Occident médiéval ${ }^{12}$. Uma passagem da «Introduction» (pp. 9-17) elucida-nos sobre o percurso intelectual de BG na feitura da obra: «(...) I'étude de I'histoire politique m'a persuadé qu'en définitive la vie et la solidité des États dépend moins de leurs institutions que des idées, des sentiments et des croyances des gouvernés. Mais ces mentalités politiques eIles-mêmes ne sont-elles pas largement façonnées par le passé

\footnotetext{
${ }^{6}$ GUENÉE, 1968.

${ }^{7}$ In AUTRAND, Françoise [Ed.] - Prosopographie et genèse de l'État Moderne, Paris ENSJF, 1986: 249-79

${ }^{8}$ Bullettino dell'lstituto Storico Italiano per il Medio Evo e Archivio Muratoriano, 94 (1988)]: 439-470.

${ }^{9}$ Journal des Savants (1989, juil.-déc.): 241-57.

${ }^{10}$ GUENÉE, 1981.

${ }^{11}$ GUENÉE (Dir.), 1977.

${ }^{12}$ GUENÉE, 1980.
} 
que chacun se croit? Un groupe social, une société politique, une civilisation se définissent d' abord par leur mémoire, c' est-à-dire par leur histoire, non pas I'histoire qu'ils eurent vraiment, mais celle que les historiens leur firent. Désireux de comprendre I'histoire du Moyen Âge, il m'a semblé indispensable de considérer non seulement l'histoire au Moyen Âge, mais aussi le poids qu'elle put avoir. Je suis intéressé par I'historien, mais plus encore par son public; par I'oeuvre historique, mais plus encore par son succès; par I'histoire, mais plus encore par la culture historique» (p. 16). E seguem-se 8 capítulos, lembrando, em termos de perspectiva, o que um manual actual de metodologia da História será em termos de preceptiva: «O que é a história?», «Perfis de historiadores», «O trabalho do historiador» (três capítulos, intitulados, sucessivamente, A documentação, A elaboração e A composição), «O sucesso da obra», «A cultura histórica» e «O peso da história». E uma lapidar Conclusion (pp. 357 ss.), onde, a fechar (p. 367), se afirma o seguinte: «(...) tout mon livre a (...) tendu à montrer; à travers les âges, la continuité de I'effort historique, la solidarité de tout ces historiens qui ont voulu retrouver (...) et dire le passé. Et dans cette longue chaîne de solidarité, les mille ans que I'on appelle le Moyen Âge ne représentent pas une rupture. Fiers d'être nous-mêmes historiens, cessons de voir avec condescendance ces temps peuplés de naïfs conteurs. Certains le furent. Mais beaucoup d'autres ne furent rien de moins que nos lointains "camarades" ${ }^{13}$, nos dignes collègues (...)».

Talvez seja este o domínio mais intensamente presente na Obra ulterior de BG: No imediato, aclarando ao longo dos anos questões como a dos «géneros históricos» ou a da génese e desenvolvimento da crónica (cf. «Les premiers pas de l'historiographie en Occident au Xl1 ${ }^{\mathrm{e}}$ siecle» ${ }^{14}$; «Histoire, mémoire, écriture. Contribution à une étude des lieux communs» ${ }^{15}$; ou ainda «Grandes (Les) Chroniques de France. Le Roman aux roys (1274-1518)» ${ }^{16}$. Mais recentemente, dedicando-se ao estudo da Crónica do «Religieux de SaintDenys», cuja reedição prefaciou ${ }^{17}$. Trata-se de um texto cronístico da viragem do século XIV para o XV; o autor está identificado, há cerca de 20 anos, como sendo

\footnotetext{
${ }^{13}$ Expressão tomada de empréstimo a DUBY, Georges; LARDREAU, Guy - Dialogues, Paris, 1980: 87

${ }^{14}$ Académie des Inscriptions et Belles-Lettres. Comptes rendus des séances [1983, janv.-mars]: 136-52.

${ }^{15}$ Ibid. (1983, juil.-oct.): 441-456.

${ }^{16}$ In NORA, Pierre [Dir.] - Lieux (Les) de Mémoire, II. La Nation, t. I, Paris, Gallimard, 1986: 189-214.

${ }^{17}$ Chronique du Religieux de Saint-Denys contenant le règne de Charles VI de 1380 à 1422, reimpr., em 3 vols., da ed. bilingue Louis-François BELLAGUET [1839-1852], Paris, CTHS, 1994; Introduction de BG, com o título «Michel Pintoin, sa vie, son oeuvre», vol. 1: I-LXXX
} 
Michel Pintoin [MP] ${ }^{18}$, eclesiástico que terá vivido entre ca. 1349 e 1421, sendo chantre da abadia a partir de ca. 1400. A obra, cujo encargo terá sido cometido a MP entre 1388 e 1392, foi elaborada entre ca. 1394 e o Outono de 1420, pouco antes da morte do autor. Na referida «Introduction», BG tem sucessivamente em conta: a edição oitocentista da Crónica e os contributos da Historiografia ulterior (pp. 1-V); a vida e obra de MP e a sua integração na produção 'literária' do «atelier historiográfico de Saint-Denis» (pp. V$\mathrm{XXX}$ ); os manuscritos da obra (pp. XXX-XXXIII); os processos de trabalho do autor (pp. XXXIII ss.), as suas fontes (documentação, informações provenientes da Corte, do mundo universitário...) e o modo como as utiliza; o texto de $\mathbf{M P}$ - incluindo o peso que a biografia do autor e da sua vivência dos eventos que narra nele terão -, o seu estilo, a sua utilização da língua latina, a sua concepção de História (narração dos factos e relações de causalidade entre os mesmos, memória, ensinamento), a estruturação da obra (em moldes que plenamente justificam a sua classificação como crónica), os processos narrativos (com a utilização de casus, cada um dos quais com um princípio e um fim), a sua retórica (e as aproximações a Salústio, Cícero, Juvenal, Ovídio ou, sobretudo, Tito Lívio): terminando BG (pp. LXIX-LXXII) com os destinos ulteriores de Saint-Denis e da cronística régia francesa, até à renovada atenção do século XVII pela obra de MP e pela sua Crónica de Carlos VI, mormente com a tradução em 1663 por Jean Le Laboureur. Rematando BG (p. LXII): «Près de deux siècles plus tard, LouisFrançois Bellaguet publiait le texte latin et une nouvelle traduction française de la Chronique de Charles VI. On n 'ose pas espérer que, pour remplacer l'un et I 'autre, deux siècles, à nouveau, suffiront».

Esta obra tem marcado de forma considerável a produção recente de $\mathbf{B G}^{\mathbf{1 9}}$. Domínio este - o da História da Historiografia Medieval - onde a acção continuada de BG e de tantos outros na sua sequência permitem mesmo o sonho: «On rêve que toutes ces recherches additionnées puissent un jour aboutir à un tableau précis, par exemple, de

\footnotetext{
${ }^{18}$ Cf. GRÉVY-PONS, Nicole; ORNATO, Ezio - «Qui est l'auteur de la chronique latine de Charles VI dite du Religieux de Saint-Denis?», Bibliothèque de l'École des Chartes, 134 [1976]: 85-102.

${ }^{19}$ Cf.: «Tragédie et histoire chez le Religieux de Saint-Denis», Bibliothèque de l'École des Chartes, 150 (1992): 223-44; «Le Religieux et les docteurs. Comment le Religieux de Saint-Denis voyait les professeurs de I'Université de Paris», Académie des Inscriptions et Belles-Lettres. Comptes rendus des séances (1992): 675-86; «Un royaume et des pays: la France de Michel Pintoin», in BABEL, Rainer; BABEL, Jean-Marie [Ed.] - Identité régionale et conscience nationale en France et en Allemagne du Moyen Âge à l'époque moderne, Sigmaringen, Jan Thorbecke Verlag, 1997, pp. 403-412).
} 
l'histoire et de la culture historique des Français sous Charles VI» ${ }^{20}$. E mais adiante, fechando o mesmo texto: «L'histoire de l'historiographie médiévale a déjà fait beaucoup. Il lui reste beaucoup à faire. On souhaite (...) la faire un peu avancer sur un long chemin ${ }^{21}$.

3) Finalmente, os seus dois livros mais recentes (Entre l'Église et l'État. Quatre vies de prélats français à la fin du Moyen Âge $\left(\mathrm{XIII}^{\mathrm{e}}-\mathrm{XV}^{\mathrm{e}} \text { siècle }\right)^{22}$; e Un meurtre, une société. L'assassinat du duc d'Orléans, 23 novembre $1407^{23}$ ) constituem ensaios de resposta - só possíveis na pena de um autor maduro e com vasta obra prévia - a questões (talvez) à partida algo provocatórias:

- Poderia um novo historiador dos poderes, pioneiro dos estudos prosopográficos, praticar a biografia singular? Ou exercitar o retorno ao acontecimento?

A primeira questão está patente no livro de 1987. Numa relativamente longa «Introduction» [pp. 7-47], BG aborda o problema das relações entre História e Biografia(s); questiona a história de uma vida enquanto exemplar ou singular; recorda a sua experiência de prosopógrafo e as limitações de tal método («... il me semble aujourd'hui que ces études prosopographiques ont, au moins pour le Moyen Âge, quelque chose de frustrant. Elles permettent d'atteindre des carrières, mais non pas des personnes. On sait ce que ces gens ont fait ou possédé, mais non pas ce qu 'ils ont espéré ou craint, aimé ou haï» [p. 15]). Solução? Talvez a renúncia à exaustividade dos catálogos prosopográficos e o recentramento numas tantas individualidades que possam ter deixado traços de si próprias, ou seja, «a élite dos que escrevem» [Ioc. cit.]. Recordando a origem escolar do livro (um curso sobre Igreja e Estado nos finais da Idade Média para candidatos à agrégation [1983]), BG propõe-nos um percurso pela História política e eclesiástica francesa, da Cruzada de S. Luís (1244) [p. 16] às «concordatas» de 1472 e de 1516, «consagrando a existência de uma Igreja galicana submetida ao Rei», um Rei «soberano de um Estado forte e senhor de uma Igreja

${ }^{20}$ Cf. «Introduction» a GENET, Jean-Philippe [Ed.] - Historiographie (L') Médiévale en Europe, Paris, CNRS, 1991: 17

${ }^{21}$ Ibid.: 18 .

${ }^{22}$ GUENÉE, 1987.

${ }^{23}$ GUENÉE, 1992. 
devotada» [p. 18]. Tudo isto através das vidas de 4 prelados: Bernard Gui (1266-1331) [pp. 49 ss.]; Gilles Le Muisit (1272-1353) [pp. 87 ss.]; Pierre d'Ailly (1351-1420) [pp. 125 ss.]; e Thomas Basin (1412-1490) [pp. 301 ss.]. Vidas abordadas de forma «solidária e encadeada», e tendo em conta o que de social e de pessoal poderia pesar no «cursus honorum» de um homem de Igreja e/ou de Estado no reino da França dos finais da Idade Média: e assim a «lntroduction», na sua segunda parte [pp. 20 ss.], tem sucessivamente em conta circunstâncias como «nascimento», «ambição», «saber e talento», «familiares e amigos», «zelo e obediência», «receio e medo» e «idade e experiência».

Relembrando no final o debate (por vezes impossível) entre estudo estrutural/compreensão da História e narração de vidas/sentir da História, BG chega a citar a «boutade» de Anatole France, associando a «história estatística» a uma mera «autópsia». Para concluir [p. 47]: «L'histoire statistique (...) est à I'histoire narrative ce que la pomme de terre est à la rose. Pour ma part, en écrivant ces quatre vies, je n 'ai pas voulu substituer des roses aux pommes de terre qui m' ont nourri si longtemps. J'ai voulu, dans ces biographies, réconcilier la rose et la pomme de terre».

Diverso é o percurso proposto pelo livro de 1992. A «lntroduction» [pp. 7-16] é agora mais breve; mas tem um ponto em comum com a do livro precedente: a fechar a dúzia de páginas que arranca na narração do ocorrido ao princípio da noite parisiense de 27 de Novembro de 1407 - o assassínio do duque de Orleães pelo duque da Borgonha -, de novo uma referência literária, agora Paul Valéry, acerca do entediante acontecimento, mera «espuma das coisas», antes lhe interessando o mar: «é aí que se pesca». Contrapõe BG: «... l'écume, les vagues et la mer sont une seule et même chose. Le pêcheur pêche dans la mel: Et I' historien, comme lui, doit envoyer ses filets profond. Mais le pêcheur ne courait-il pas quelque danger à ne pas se soucier de I' écume et des vagues? De même l'historien, à négliger les événements» [p. 16]. E daí o programa para o livro: partir de um «acontecimento exemplar» - e da sua sequência de 12 anos, até à vingança, consumada a 10 de Setembro de 1419 - para «mieux éclairer les structures et les mentalités politiques en France à la fin du Moyen Âge». Comporta a obra 11 capítulos, agrupados em duas partes (Une société e Un meurtre). Primeira parte (caps. I - V) tendo 
sucessivamente em conta «Imagens» (pp. ] 9 ss.), «Hierarquias» (pp. 25 ss., onde se aborda o Rei face a Deus, aos seus familiares, aos nobres e aos súbditos), «Ordem» (pp. 46 ss.), «Desordem» (pp. 71 ss.) e «Remédios» (pp. 101 ss.); segunda parte (caps. VIXI) compreendendo «Retratos» (pp. 121 ss.), «Tensões (1400-1406» (pp. 152 ss.), «Assassínio (1407)» (pp. 176 ss.), «Tempestades (1408-1415» (pp. 180 ss.), «Debates (1413-1416»> (pp. 232 ss.) e «Vingança (1415-1419» (pp. 265 ss.). Rematando a obra um breve epílogo (pp. 283-289), onde se conclui por 1407, na visão dos súbditos de Carlos VI e na análise do historiador actual, enquanto evento que pôs termo a um tempo relativamente pacífico - contrariamente a situações coevamente vividas na Península Ibérica, na Inglaterra e na Itália -, preludiando em 8 anos a derrota de Azincourt e em 12 um assassínio «ainda mais horrível». E mesmo a fechar [p. 289]: «On s'étonne un peu que le 23 novembre 1407 n'ait pas été retenu parmi les "trente journéees qui ont fait la France" [Referência a uma colecção em tempos publicada pela Gallimard; integrou, por ex., Le dimanche de Bouvines, de G. Duby]. Il devrait, à coup sûr; figurer parmi les dix journées qui ont failli la défaire».

Assim sumariamente enunciadas as facetas essenciais da obra de BG, cumpre salientar que elas consubstanciam um percurso coerente, traduzível na já mencionada expressão «das sociedades às mentalidades políticas» (cf. o ponto 1. desta nótula). De formação haurida numa ENS e numa Sorbonne do imediato post-Guerra - ainda com ecos de Ferdinand Lot (1866-1952) - prolongado no por vezes esquecido Robert Fawtier (18851966) -, a presença terminal de Louis Halphen (1880-1950) e o ensino de Perrin e Boutruche -, não surpreende a dimensão institucional das suas teses de doctorat; que no entanto, e através da prosopografia, articulam o político e o social. A sequência consubstancia um caminho do Estado aos poderes, da instituição à representaçãolegitimação-propaganda. Ou, se preferirmos, do político / politológico ao político / antropológico; com o que isso possa representar de aproximações à «Nouvelle Histoire» stricto sensu. Entendamo-nos sobre este ponto. Torna-se-me difícil falar de retornos (do político, do biográfico, etc.) quando se trata de encarar a «nova História política» medieval francesa com um cunho escolar sorbonnard, chartiste, da EPHE (IV Secção) ou da ENS. Por alguma razão um Charles-Olivier Carbonell salientou que tais caminhos da Historiografia vinham na sequência da «Nouvelle Histoire» e não em ruptura com 
ela $^{24}$. De acordo. Mas há que salientar que BG - como tantos outros da mesma «galáxia» dos saberes de Clio - é um autor para quem «fazer História» é quase sinónimo de «fazer Escola»; com o que isso representa de atenção ao legado dos maiores e à criação de descendência científica; tudo isto num clima de solidariedade e de convivialidade, que contrastam com a postura não raro jactante dos actuais avatares da École des Hautes Études en Sciences Sociales [EHESS]. E não será por acaso que «bienveillance» é termo tão ocorrente nas referências gratulatórias dos seus alunos de doctarat.

E assim se compreende a dimensão do discipulado de BG. O manual Nouvelle Clio (1971), nas suas múltiplas edições e tiragens, tem sido veículo da aprendizagem de múltiplas gerações escolares, na França e fora dela (e apontem-se as traduções espanhola e portuguesa [Brasil]). E algo de semelhante se diga de Histoire et Culture Historique (1980).

Por outro lado, enquanto História institucional do Estado e da Igreja (ou da relação entre as duas entidades), a sua obra prolonga-se, por exemplo, numa Françoise Autrand (e nos seus trabalhos sobre o Parlamento de Paris), numa Claude Gauvard, sua sucessora em Paris I (e nos seus estudos sobre criminalidade e remissão régia), numa Hélène Millet ou numa Elisabeth Mornet (e nos trabalhos que continuadamente têm realizado sobre capítulos catedrais), ou ainda num Alain Demurger (autor de múltiplos trabalhos sobre geografia política tardo-medieval: viscondes, bailios, senescais - particularmente na Normandia - e respectivas carreiras) ou num Olivier Matteoni (a quem se devem valiosos estudos sobre, por exemplo, a Chambre des Comptes de Moulins). Enquanto historiador dos proto-sentimentos nacionais ou das ideias sobre o poder, BG tem sido continuado por uma Colette Beaune (estudiosa do nascimento da França enquanto nação), por um Jacques Krynen (um jus-historiador a quem se devem obras fundamentais sobre ideal do Príncipe / ideário sobre o Príncipe) ou por um JeanPhilippe Genet [que, ao estudar as ideias políticas na Inglaterra de finais da Idade Média, retoma uma tradição anglóloga do medievismo francês, interrompida desde o

\footnotetext{
${ }^{24}$ CARBONELL, Ch.-O. - «Origines (Les) de I'État moderne: les traditions historiographiques françaises (1820-1990)», in BLOCKMANS, Wim; GENET, Jean-Philippe [Ed.] - Visions sur le développement des États européens. Théories et historiographies de l'État moderne, Roma, École Française de Rome, 1993: 297-312, maxime 310.
} 
desaparecimento de Édouard Perroy (1901-1974); de realçar também o seu papel incomensurável como dinamizador de programas vários sobre Génese/Origens do Estado Moderno [no quadro do CNRS francês ou da European Science Foundation], ou enquanto sistematizador da utilização da Informática nos estudos de História política medieval). O historiador da Historiografia tem tido em Jean-Marie Moeglin, seu sucessor na EPHE, um dos continuadores. Enquanto que as abordagens monobiográficas têm tido sequência, por exemplo, nos livros que Françoise Autrand dedicou a Carlos V e a Carlos VI.

Destaque-se, por último, a audiência profunda que a obra de BG tem tido entre nós. Nunca tendo, infelizmente, podido visitar Portugal ${ }^{25}$, sendo escasso o seu conhecimento directo de historiadores do nosso País, a sua influência é no entanto assinalável:

- $\quad$ Salientem-se, na Escola de Coimbra, alguns dos trabalhos recentes de $\mathrm{M}^{\mathrm{a}}$ Helena C. Coelho (v.g. a monografia sobre D. Gonçalo Pereira, arcebispo de Braga) ou a tese de Leontina Ventura sobre a nobreza de Corte de Afonso III);

- $\quad$ salientem-se, na U. Porto, os trabalhos de Armindo de Sousa (1942-1998) sobre as nossas Cortes de Quatrocentos, os do autor destas linhas sobre a burocracia régia e os seus oficiais ou sobre a legislação dos nossos monarcas, os de Luís Miguel Duarte sobre criminalidade, justiça e perdão régio e os de José Augusto Pizarro sobre nobreza dionisina;

- e salientem-se, na U. Nova de Lisboa, a dimensão históricohistoriográfica das obras de José Mattoso e de Luís Krus (1954-2005) (ainda que, provavelmente, estes dois autores vejam como seus preferenciais referenciais um Jacques Le Goff, um Jean-Claude Schmitt ou um Alain Boureau, por exemplo, sem esquecer entretanto «O último» Georges Duby [1919-1996]), bem como a tese de Rita Costa Gomes sobre a nossa «sociedade de Corte» tardo-medieva.

\footnotetext{
${ }^{25}$ Nota de actualização: Viria a visitar-nos em Novembro de 2004, participando, na FL/UP, na Semana de Estudos Medievais votada à problemática «Biografias régias: experiências e projectos».
} 
Tal, pelo menos, o balanço possível pela pena de alguém que no Verão de 1972 recebeu de um dos seus Mestres a indicação de leitura de L'Occident aux XIV $V^{e}$ et $X V^{e}$ siècles. Les États; e que a partir de então não mais perdeu de vista o Autor respectivo, a sua Escola e as suas filiação e descendência intelectuais.

Quase em simultâneo com a saída do volume em sua homenagem, resultante de um colóquio realizado aquando da jubilação universitária ${ }^{26}$, Bernard Guenée publica Un Roi et son Historien. Vingt études sur le règne de Charles VI et la Chronique du Religieux de Saint-Denis ${ }^{27}$, reeditando um total de 18 estudos dados à estampa entre 1988 e 1999, acrescidos de dois ainda inéditos; tudo antecedido de uma «lntroduction» (pp. 7-30) e sucedido de uma extensa bibliografia (pp. 479 ss.), de uma relação das passagens de Guillaume de Tyr retomadas pelo «Religieux de Saint-Denis»[Michel Pintoin, doravante MP] (pp. 495 ss.) e por índices onomástico, toponímico, de expressões latinas e de referências à Chronique du Religieux de Saint-Denis (pp. 501 ss.).

Percorramos rapidamente a «lntroduction». BG começa por recordar brevemente o seu percurso post-doutoramento (1963): o volume para a «Nouvelle Clio» sobre os Estados de finais da Idade Média ${ }^{28}$ e a subsequente passagem às mentalidades políticas e à Historiografia da Idade Média Ocidental, notavelmente consubstanciada em Histoire et Culture Historique ${ }^{29}$.

\footnotetext{
** A secção que agora se inicia reedita com adaptações a r.c. a GUENÉE, 1999, Revista da Faculdade de Letras [UP]. História, III sér., 2 (2001), pp. 224-230.

${ }^{26}$ Cf. AUTRAND, Françoise; GAUVARD, Claude; MOEGLIN, Jean-Marie (Ed.); 1999 - Saint-Denis et la Royauté. Études offertes à Bernard Guenée, membre de l'Institut, Paris, Publications de la Sorbonne.

${ }^{27}$ GUENÉE, 1999.

${ }^{28}$ GUENÉE, 1998.

${ }^{29}$ GUENÉE, 1991.
} 
Mas o tempo das sínteses passara, apesar do prazer sentido na elaboração daquelas obras, hoje clássicas: «Un jour vint ou il m'a paru nécessaire de contrôler et de nuancer les idées qui avaient pu me venir dans les vingt années précédentes, de les lester de réalités mieux appréhendées, dans un cadre plus limité» (p. 8). O «fascínio» pelo reinado de Carlos VI (1380-1422) fez o resto, aliado à atitude intelectual de quem considera que um historiador, independentemente das obras de síntese que possa produzir, jamais deverá esquecer a erudição: «Les dépouillements d'archives, l'étude de documents longtemps publiés et depuis longtemps oubliés, la lecture attentive d' articles érudits et de livres austeres sont nécessaires pour que levent les idées de l'historien, et qu' elles éclairent sans les trahir les complexités du réel. Or, pour la période que je venais de considérer, il était clair que malgré des syntheses méritoires et de remarquables travaux ponctuels, toutes les archives disponibles étaient loin d'avoir été dépouillés, toutes les éditions nécessaires étaient loin d'avoir été donnés, les textes publiés étaient loin d'avoir livré leurs secrets. Le long règne de Charles VI apparaît encore aujourd'hui comme une immense chantier. Il m'a paru bientôt nécessaire de mettre ce que j'avais pu apprendre d'histoire politique et d'histoire de l'historiographie à l'épreuve d'un texte fondamental pour la connaissance du règne de Charles VI, la Chronique du Religieux de Saint-Denis» (p. 8).

Precisando depois todo o seu programa de trabalho em torno de Carlos VI e do seu cronista (pp. 8-11), aproveitando para algumas «mises au point» dos textos que depois reedita (pp. 11 ss.), BG finalizará com uma passagem de Ernest Renan sobre a efémera validade das ciências históricas, por maior que seja a «precisão» dos seus cultores (p. 30).

Os 20 estudos que o volume inclui estão agrupados em 4 secções:

I. «MP et sa Chronique de Charles VI»;

II. $\quad$ Le roi Charles VI»;

III. «La France de Charles VI»; e

IV. «Quelques instruments de la vie politique». 
Examinemos brevemente, para cada secção, alguns dos trabalhos, mormente em função da condição que possam ter de lições de método.

Na secção I. o meu destaque vai para o texto 5., «Fiction et réalité dans l'oeuvre du Religieux de Saint-Denis: l'exemple de la paix de Tournai (1385)» ${ }^{30}$. Depois de passar em revista as boas e más «reputações» de MP na viragem do século XIX para o XX com base na ed. bilingue de L.-E Bellaguet (1839-1852) ${ }^{31}$, BG opta por um caso: a narração da paz de Tournai (1385). Este evento coroa um conflito, remontando a 1382, entre os Flamengos e o seu conde, Luís de Male. A hoste real francesa acaba por intervir na questão, pelo facto de o duque da Borgonha, Filipe o Ousado, tio do então adolescente (14 anos) Carlos VI, ser casado com a filha única do conde da Flandres. Militarmente, o ano de 1382 assistira a derrotas dos revoltosos em Roosebeke, Ypres e Bruges. Em 1384, por morte de Luís de Male, Filipe o Ousado tornara-se conde da Flandres. Subsistia no entanto a insubmissão de Gand. Só no Verão de 1385 se esboçam os caminhos pacificadores, tudo culminando no tratado assinado em Tournai, em 18 de Dezembro do mesmo ano. O instrumento que consubstancia esta paz é uma carta de Filipe, publicada em toda a Flandres e amplamente difundida; Froissart transcreveu-a na íntegra.

O mesmo fará MP anos decorridos: depois de lembrar que a Crónica do Religioso de St.-Denis terá sido iniciada entre 1394 e 1398 (logo, entre 10 a 15 anos decorridos sobre os acontecimentos flamengos que culminaram na paz de Tournai), BG debruça-se sobre a versão de MP da carta do duque da Borgonha: uma tradução «exacte et précise» (pp. 166-167); mas não total, como se fará notar logo de seguida: de facto, o Religioso não só não transcreverá o preâmbulo outorgante de Filipe - limitando-se à declaração «humilde» de aceitação pelos cidadãos de Gand das «graces, pardons et clemences» recebidas de Carlos e Filipe -, como, ao traduzir as cláusulas da paz, substitui graça e perdão por «un mot aussi peu juridique que possible: indulgentia» (p. 167). Para além de que, a versão de MP dos acontecimentos que precederam a paz nada tem de verosímil: ignorando como é que em Gand «le parti de la paix l'a emporté», o

\footnotetext{
${ }^{30}$ Pp. 163-170. Publ. original: 1993.

${ }^{31}$ Reed. em 3 tt. em 1994, com Introdução de BG.
} 
Religioso, «nouveau Salluste», dá a palavra a um anónimo ourives que mais ninguém refere, exortando os concidadãos à não-resistência ao senhor natural, mas antes ao pedido da sua clemência (clemenciam) e perdão (veniam) (p. 167); no mesmo contexto, não faltam as citações e paráfrases de excertos morigerantes de Cícero; como também não faltam frases exaltatórias do rei e da majestade real, da eminência régia, do régio arbítrio. O modo como os embaixadores de Gand se apresentam em Tournai - montados em cavalos adornados (phaleratis), uniformizados e com grande pompa (apparatu pomposo) (p. 168) $)^{32}$ - é qualificado de passivum scandalum - utilizando aqui um conceito («escândalo») ausente do latim clássico, proveniente do grego e já corrente na Vulgata, e uma distinção (escândalo activo / passivo) recolhida de S. Tomás -, mas de que os cidadãos de Gand se souberam redimir quando na presença do rei, perante quem se prosternaram e a quem humildemente suplicaram o perdão dos erros; o rei teria aprovado as condições da paz, fazendo elaborar o acto escrito consignatório em nome de Filipe e de sua mulher. Só que Carlos VI quase não deixou Paris em Dezembro de $1385 \ldots$

(Quase) Concluindo: «Nous voyons mieux maintenant comment le Religieux de SaintDenis a écrit l'histoire. Certes, il doit bien tenir compte des faits. Mais son principal souci n' est pas, comme Froissart, de donner un beau récit. Ce qu'il veut d'abord, c'est bien exposer une théorie. Il ne s'agit pas pour lui de dire ce qui a été, mais ce qui aurait dû être» (p. 170). O Religioso procura assim impor a ideia da majestade real e da sua preeminência na sociedade política; o perdão (face outra da punição) é uma das facetas essenciais da justiça régia, geradora da paz. E daí a quase exclusão de Filipe, duque da Borgonha e conde da Flandres, da outorga de um acto conscripcionado em seu nome. E (mesmo) a fechar: «Il convient donc ne point mal user du grand historien qu'est le Religieux de Saint-Denis. Si nous entendons enrichir notre récit de détails qu'il donne seul, nous le faisons à nos risques et périls. Ce sont des idées, et non des réalités, qu'il faut chercher dans le récit de Michel Pintoin. Son histoire n'est pas une carrière de faits assurés. C'est la mise en scène chronologique d'une idéologie» (p. 170).

\footnotetext{
${ }^{32}$ A pompa seria, segundo o vocabulário do Religioso, reservada ao aparato real.
} 
Dois destaques na secção 1I.: os textos 8., «Le voeu de Charles VI. Essai sur la dévotion des rois de France aux $\mathrm{XII1}^{\mathrm{e}}$ et $\mathrm{XIV}^{\mathrm{e}}$ siècles» ${ }^{33}$, e 9., «La folie de Charles VI. Étude de mots $»^{34}$.

O primeiro destes trabalhos deriva do Seminário ministrado por BG na École Pratique des.

Hautes Études em 1994/95. Escreve o Autor, a abrir:

«Le 5 août 1392, à la sortie du Mans, le roi Charles VI sombre pour la première fois dans la folie. C'est seulement trois jours après, nous dit le Religieux de Saint-Denis, qu'il retrouva l'usage de la raison. Alors, il se confessa, assista à la messe, communia, et, ajoute Michel Pintoin, "il fit un voeu à sainte Marie et à saint Denis. Il promit d'aller visiter leurs églises lorsqu'il aurait retrouvé la santé"» (p. 219).

Que significado, o de um tal voto, na França de finais de Trezentos? Nada tem de surpreendente o que toca Saint Denis: o texto do Religioso abunda em referências ao primeiro bispo de Paris, glorioso mártir, apóstolo da França; nada de inesperado, neste ponto, no voto de Carlos VI.

Já o voto à Virgem poderá, à partida, surpreender, numa Idade Média francesa em que o único rei devoto de Maria pareceria ser Luís XI (p. 220) ${ }^{35}$ e em que a consagração do reino à protecção da Virgem viria somente com Luís X1ll (1638). Para esclarecer o duplo voto de Carlos VI, BG faz um survol sobre a devoção dos monarcas medievais franceses, com especial detença nas épocas de Carlos V e de Carlos VI. Passemos por alto os tempos que vão dos alvores do século XII à canonização de Luís IX (1297). Quando esta se dá, os três hauts lieux do culto ao rei-santo são Saint-Denis, a SainteChapelle e - significativamente - Notre-Dame de Paris (p. 230).

Em 1304, Filipe o Belo dar-nos-á uma como que antevisão do voto de Carlos VI: vitorioso sobre os flamengos em Mons-en-Pévèle, o monarca agradece conjuntamente a

${ }^{33}$ pp, 219-275. Publ. original: 1996.

34 pp. 277-283. Publ. original: 1995.

35 A par, no entanto, de diversos outros santos. 
Notre-Dame e a Saint Denis, «spécial protecteur du royaume de France»; mas além da abadia de Saint-Denis, determina celebrações futuras em Notre-Dame de Boulogne, Notre-Dame de Paris e Notre-Dame de Chartres; e eis um Filipe o Belo devoto de seu avô e da Virgem, mas prestando devoção a esta última sobretudo em igrejas catedrais (pp. 231-232). E o primeiro Capeto-Valois, Filipe VI, vitorioso sobre os flamengos em CasseI (1328), «a pratiquement mis ses pas dans ceux de Philippe IV», neste caso em Chartres (pp. 232-233).

Nos momentos quentes da revolta parisiense de Étienne Marcel (1358), o delfim Carlos, futuro Carlos $\mathrm{V}^{36}$, e os parisienses que lhe permanecerão fiéis não duvidarão de que a vitória sobre os inimigos se deveu a Cristo, à «sa benoicte doulce mère» e a Saint Denis (p. 239). Em momentos diversos do seu reinado, este rei que fôra duque da Normandia, visitará Notre-Dame de Ruão, e também Notre-Dame de Chartres e Notre-Dame de Paris, aí orando e por vezes instituindo missas; e na catedral parisiense e em Saint-Denis o rei dará graças em Dezembro de 1368 pelo nascimento do seu varão primogénito, futuro Carlos VI (pp. 240-242) ${ }^{37}$. E num balanço final sobre a devoção do rei em causa, BG escreve:

«Au total, la dévotion de Charles V, où se conjuguent tradition et innovation, nous apparaît comme une dévotion profonde, bien ordonnée, minutieusement organisée. Et de cet ensemble complexe et structuré se détachent deux saints, Notre-Dame et saint Denis, deux lieux, Notre-Dame de Paris et Saint-Denis en France, et les trois moments essentiels d'un cycle dévotionnel qui mène le roi à Saint-Denis en France le 24 février et le 9 octobre, et à Notre-Dame de Paris le premier dimanche de I'Avent» (p. 257).

Algo parece desestruturar-se na menoridade de Carlos VI (1380-1388) (pp. 260 ss.): se bem que dizendo quotidianamente as suas horas, o jovem monarca parece sobretudo devoto de Santa Inês - em cujo dia nasceu - e de S. Cosme e S. Damião. E mesmo em contextos de vitória militar, o que transparece do texto de MP é a exaltação do oriflamme e a devoção a Saint Denis, com omissões de visitas do rei à catedral

\footnotetext{
${ }^{36} \mathrm{O}$ rei João o Bom está prisioneiro em Inglaterra.

${ }^{37}$ A pp. 243 ss. vejam-se as peregrinações (25 na totalidade do reinado) e as dotações régias ao tesouro de Notre-Dame de Paris na sequência do nascimento do delfim.
} 
parisiense; à qual, de qualquer modo, não parece dirigir-se pessoalmente ao iniciar o seu governo pessoal em Novembro de 1388, em Reims, pouco antes de completar 20 anos; ao que parece, desde 1380 que não entrava na catedral; na circunstância, coube ao chanceler e ao bispo de Evreux uma visita a Notre-Dame em nome do soberano (p. 264).

Os primeiros acessos da loucura real parecem ser assim a causa do retorno às práticas devocionais de Carlos V. Ainda que sem referências em MP, o certo é que Carlos VI visita diversas vezes a catedral parisiense a partir da convalescença da sua primeira crise (Outono de 1392); o mesmo faz, é certo, à abadia de Saint-Denis; mas em poucos meses «La mystique de l'oriflamme [...] était oubliée» (p. 267).

Aquando da sua segunda crise (Jun.1393 / Jan.1394), Carlos VI fará voto a S. Miguel Arcanjo. Restabelecido, peregrinará ao Mont-Saint-Michel (Fev.1394); entretanto, em Agosto do ano anterior nascera uma filha, a que foi dado o nome de Maria. E numa mal conhecida viagem ao Puy (Mar.1395), o monarca toma a iniciativa da confecção de um manto para a estátua da Virgem localmente existente. A partir do Advento de 1394 Carlos VI retoma o hábito das visitas a Notre-Dame de Paris; e aí, em Janeiro de 1397, mandará celebrar missa, nascido que fôra o seu filho Luís, duque de Guyenne, futuro delfim. E até 1397 manter-se-ão com regularidade as visitas a Saint-Denis e a NotreDame, consubstanciantes do voto de 1392 (pp. 268-273). O ano em causa assiste ao início da multiplicação dos acessos da doença e ao empobrecimento documental. Ainda assim, qualquer melhoria parece ser seguida de alguma deslocação concretizante, uma vez mais, do voto, o qual, associado aos progressos do mal régio, «avait bien fait de Notre Dame de Paris le sanctuaire privilégié de la dévotion royale» (p. 274).

A concluir, BG aponta o voto de Carlos VI como situado «dans une tradition séculaire qui avait depuis longtemps fait de Notre-Dame et de saint Denis les deux patrons conjoints du roi et du royaume de France» (p. 274). Recordando brevemente os tempos de Filipe o Belo, Filipe VI e Carlos V, o Autor relembra também a negligência da tradição devocional nos primeiros anos de Carlos VI, situação seguida, após o primeiro acesso de loucura (1392), de um retorno à devoção a Saint Denis e a Notre-Dame; o agravamento do mal, a frequência e a imprevisibilidade das crises levaram por fim ao concentrar da devoção régia na catedral da capital do reino. 
E mesmo a fechar:

«(...) après Philippe Auguste, la sainteté de Louis IX, la foi de Philippe IV, la piété de Philippe VI, la sagesse de Charles V et la folie de Charles VI avaient, chacune à son tour, contribué à façonner la dévotion du roi très chrétien» (pp. 274-275).

«La folie de Charles VI» mostra-nos um dos pontos fortes do Autor, inclusive na sua prática didáctica: as análises de vocabulário; em torno, neste caso, da consabida loucura do rei, declarada pela primeira vez em 1392, como já se viu. Tema muito frequentado, já presente em Froissart (mas só no tocante às primeiras crises), objecto de abordagem histórico-médica nos alvores do século XX, acaba no entanto por ter em MP «le seul témoin qui nous permet de suivre la folie royale de façon continue, pendant trente ans» (p. 277). Qual o vocabulário do Religioso para a loucura de Carlos VI? É este o objectivo - ainda que, aqui, sucintamente - de BG, repousando no tratamento informático do léxico da Crónica. E a questão é pertinente na medida em que «Les clercs nourris de la Bible et des Pères de I'Église, les théologiens, les juristes, les médecins et les gens ordinaires n'avaient pas sur la folie les mêmes perspectives, et n'en parlaient pas avec les mêmes mots» (p. 278). Poder-se-á dizer, sucessivamente, que MP se demarca do léxico que encara o louco como possesso do demónio (demoniaci, possessi, energumeni) ou como vítima de sortilégios (v.g. maleficiis et sortilegiis detentus), bem como do vocabulário médico (freneticus, maniacus, melancolicus) ${ }^{38}$ ou jurídico (furiosus, inducie, intermissio, intervallum).

Que léxico, então? E que perspectivas? «Pour l'essentiel, Michel Pintoin n'a sur la folie royale que le point de vue du clerc cultivé qu'il était, nourri de la Bible et des Pères» (p. 279). Na linha de Gregório Magno, MP vai encarar a caecitas mentis como uma consequência da luxúria, dos pecados de juventude (ob excessus juveniles). Só a oração e a reforma dos costumes poderiam curar o rei: «(...) on dira peut-être un jour, que la conséquence la plus remarquable de la folie de Charles VI a sans doute été de pousser les français à prier davantage encore pour leur roi. Comme la sainteté de Louis IX, la

\footnotetext{
${ }^{38}$ E o Religioso é particularmente hostil às explicações médicas.
} 
folie de Charles VI a fait beaucoup pour la religion royale» (p. 279). Clérigo culto, imbuído de concepções políticas, devoto da majestade real, MP opta assim por falar da maladie du roi, sem mais ou com pouco mais, v.g. - e por ordem crescente de ocorrência - expressões ou vocábulos como incommodo, vexatio, invalitudo ou valitudo adversa, dolor, morbus, egritudo e infirmitas. Mas a doença era mental: na linha, uma vez mais, de Gregório Magno e também do Pseudo Agostinho e de S. Bernardo, MP irá também falar de mentis obnubilacio, mentis cecitas ou de ignorancie tenebris obnubilatus (eventualmente detentus ou involutus). Concessões a uma linguagem mais vulgar também as há, embora mais pontualmente e em contextos «sui generis»: mente captus, alienatus, amencia, vesanus. Particularmente chocantes para um devoto da realeza majestática seriam as consequências da doença sobre a imagem régia de dignidade: daí que MP fale por vezes em gestos ou atitudes indecentes ou dedecentes (gestus majestatem regiam dedecentes).

Após estes «traços constantes» do testemunho do Religioso sobre a loucura de Carlos VI, BG vai facultar-nos a diegese vocabular para o texto de MP referente aos anos de 1392 a 1417. E conclui: «Notre étude (...) nous a (...) permis de commencer à saisir (...) quel regard les sujets de Charles VI ont porté, pendant trente ans, sur la maladie de leur roi. Car il n'est peut-être inutile de savoir le diagnostic qu'un médecin, en 1995, peut porter sur la maladie de Charles VI. Mais il est beaucoup plus important de savoir comment un Français, en 1395, pouvait la voir» (p. 283).

Um único destaque na secção III: o texto 11., «Le roi, ses parents et son royaume en France au XIV siècle» ${ }^{39}$.

O Autor começa por se dar conta do cuidado com que os autores contemporâneos (ou quase) de Carlos VI anotam o parentesco régio ou a proximidade ao rei (v.g. seu cavaleiro) quando a alguém de tais condições referem. Os parentes do rei eram sem dúvida uma «estrutura essencial da sociedade política». E continua:

${ }^{39}$ pp. 301-324. PubI. original: 1988. 
$\ll(\ldots)$ aux alentours de 1400, il me semble bien que les parents du roi constituent un état distinct dans la société politique française, et le plus puissant. Il me semble bien que la parenté royale au XIV siècle y est une solidarité parmi d'autres, mais la plus forte. Mon propos (...) est d'essayer de préciser les progrès de la parenté royale au $\mathrm{XIV}^{\mathrm{e}}$ siècle, et ce qu'il faut bien appeler sa faillite au XV siècle» (p. 302).

BG parte uma vez mais da análise vocabular. Assim, «parentes»e «primos» (cognati, consanguinei) podem ter um alcance lato; mas também se pode ir para a perífrase, e referir, por exemplo, «mon frère, mes oncles et mes cousins»; e como termos particularmente englobantes apontam-se «sangue», «linhagem», «casa» (pp. 302-303).

É evidente que se no âmbito da problemática em causa se toma o tempo de S. Luís como terminus a quo e o de Carlos VI como terminus ante quo, se detecta uma evolução de monta. No século XIII, os três grupos que cercavam o rei (barões, grandes oficiais e parentes) não se recobriam nem o primado pertencia aos parentes, antes aos barões. Na evolução até à época de Carlos VI, BG distingue 2 momentos:

1. Os anos finais do século XIII (1297 ss.), altura em que, para poder julgar o conde de Flandres, como vassalo infiel, Filipe o Belo nomeia de uma assentada 3 novos pares do reino (o conde de Anjou, o conde de Artois e o conde [doravante duque] da Bretanha); o parentesco, ainda que existente, não constitui argumento nesta tríplice elevação ao pariato (pp. 303-305).

2. A fase final de Carlos IV e o advento de Filipe VI de Valois, fase que assiste, complementarmente, ao desenvolvimento da mística da coroa e da mística da linhagem real; o segundo ponto está bem patente na justificação de elevações de dignidade (v.g. baronias a condados) no seio da aristocracia; e pelos anos 30 um poema de Philippe de Vitry falará pela primeira vez de «Seigneurs du sang de France» (pp. 306-309). 
Os meados de Trezentos verão entretanto surgir uma situação nova - a da ausência do rei: é a prisão de João o Bom em Inglaterra, a menoridade de Carlos VI e os seus acessos de loucura a partir de 1392. Em tais condições, os parentes «(...) auraient pu maintenir la paix et le prospérité du royaume. (...) Car les parents du roi avaient le vif sentiment de ne former qu'un corps» (p. 309).

Seria, no entanto, que a linhagem real se iria tornar «un des solides piliers de l'État moderne» (p. 312) ? É o que o século XV não vai de todo confirmar. Antes de mais porque a linhagem real é uma «multidão», nem sempre «homogénea» (p. 312); depois porque à hierarquia do parentesco viria opor-se a hierarquia da dignidade (pp. 313 ss.). Assim sendo, «(...) l'ambition, l'envie et la haine pouvaient se déchaîner» (p. 319). Quando Carlos VI morre, em 1422, os seus parentes prisioneiros desde Azincourt (1415) vão regressar; e depois haverá outros parentes. E escreve BG a fechar: «Loin de moi l'idée de prétendre que les parents du roi ne vont pas avoir leur place dans la France moderne. Mais cette place ne représentera vraiment pas grand-chose en comparaison de ce qu'ils avaient pu espérer vers 1400 . (...) au XIV siècle, le roi de France a pu espérer construire son royaume avec l'aide de ses vassaux et de ses parents; à la mort de Charles VI, il était évident que l'État moderne se construirait sans et même contre le lignage royal» (p. 324).

E um último destaque na derradeira secção: o texto 18., «Non perjurabis. Serment et parjure en France sous Charles VI» ${ }^{40}$.

A abrir: «Le mercredi 23 novembre 1407, Jean sans Peur, duc de Bourgogne, faisait assassiner à Paris, rue Barbette, son cousin germain Louis d'Orléans, frère unique du roi Charles VI. Le meurtre était horrible. Ses circonstances l'étaient plus encore. Car le dimanche précédent, le 20 novembre, les deux ducs s'étaient juré "bon amour et fraternité" avant d'entendre la messe et de communier ensemble» (p. 409) ${ }^{41}$. Meses decorridos, em Março de 1408, Jean sans Peur, pela boca do doutor-teólogo Jean Petit, procurará justificar o seu acto com a alegação de que Louis d'Orléans era um tirano; e

\footnotetext{
${ }^{40}$ pp. 409-423. Publ. original: 1989.

${ }^{41}$ Note-se que nos anos 90 BG dedicou um livro a esta ocorrência: GUENÉE, 1992.
} 
tiranicídio não seria homicídio... O que não ficará sem resposta: em Setembro do mesmo ano, o abbé de Cérisy contestará a ideia de tiranicídio, em nome dos laços que uniam os dois contendores: donde, «cruel hommicide», «traistre hommicide», «trahison abhominable», morte «desloiale» (pp. 409-410). E em 1413 Jean Gerson lutará pela proclamação como herética da tese do tiranicídio, em Paris primeiro, no concílio de Constança depois; os argumentos são dois, tirados da Bíblia e de princípios cristãos fundamentais: «Non occides»e «Non perjurabis»; ao que se acrescenta a opinião de S. Tomás e de outros doutores de que o perjúrio é pecado mais grave que o homicídio, «car le parjure met plus immédiatement en cause Dieu, qu'il avait pris à témoin» (p. 410).

O que representava então o juramento na França de Carlos VI? Cumprirá destacar a sua difusão como prática social e religiosa (pp. 411-417):

a) Presta juramento o próprio rei aquando da sagração;

b) perante ele juram os vassalos, no quadro da fidelidade e da homenagem;

c) juram os oficiais no momento da entrada em funções;

d) juram os prelados, ao tomar posse do temporal;

e) múltiplas são as circunstâncias - apenas menos frequentes - em que nos meios não-nobres se presta juramento, v.g. por ocasião de uma transacção, considerada dependente da «foy de marchandise»; o matrimónio chega a ser designado, cumulativamente, de «sacrement et serment»; e infindáveis são as ocasiões de juramento ao mais elementar nível do quotidiano;

f) acrescente-se que não faltarão as «pazes juradas» na conjuntura que se segue à morte violenta do duque de Orléans.

Tudo isto permitindo assim ao Autor o fecho deste ponto nos seguintes termos: «Des théologiens français pouvaient d'ailleurs rappeler que deux Rois de France, malgré ce qu'il en avait coûté, avaient tenu parole à leurs ennemis (...). Et ses sujets [leur] 
avaient donné raison, puisqu'ils avaient la conviction profonde que le serment était le seul garant de l' ordre et de la paix, dans le royaume et entre les nations» (pp. 416-417).

Simplesmente, a realidade tinha outra face: «(...) si le serment était (...) fréquent, (...) le parjure ne l'était pas moins» (p. 417). E pelas mais diversas razões, em boa parte tendo a ver com as três condições implícitas de qualquer juramento: «judicium, justitia, veritas» (p. 418); pelo que:

a) «Un serment ne peut non plus aller contre l'ordre de la charité (...). On ne saurait s'obstiner à respecter un serment qui tournerait au préjudice de ceux qu'on aime» (p. 418);

b) «Un serment ne saurait obliger à faire quelque chose de nuisible» (idem);

c) «(..) un serment n'a pas a être tenu si les choses ne restent pas en l'état» (idem);

d) «Ainsi s'accumulaient les raisons qui permettaient de ne pas tenir un serment, et surtout un serment prêté à un tyran» (idem);

e) «La triste réalité (...) [:] ni en fait, ni en droit, le serment n' était le fondement assuré sur lequel reposait la société. Le serment était quotidien. Mais le parjure l' était aussi. Il était même souvent licite» (p. 421).

De tal modo, «La faillite du serment sous Charles VI obligeait alors à s'interroger sur son importance réelle dans la société politique» (p. 422). BG lembra que Baldo já observara que a fé antiga não necessitara de juramentos de fidelidade. Só a imperfeição moral justificaria «l'obligation de serment et de jurement» (idem). Pelos finais da Idade Média, J. Gerson admitia que a vida pública precisava menos de juramentos que de «loyal amour»e de «bonne foy» (idem).

E mesmo a concluir: «Pendant des siècles, la société politique avait tenté de s'appuyer sur des contrats, des amités, des alliances confirmés par des serments. Les serments s' étaient peu à peu multipliés. Ils étaient devenus, sous Charles VI, presque quotidiens. 
Mais cette fréquence ne faisait que souligner leur impuissance. Beaucoup se rendaient maintenant compte que mieux valait tenter de construire la société politique sur ce qu'imposaient des obligations naturelles comme la parenté ou la sujétion. Le temps de Charles VI, avec tous ses drames, avec ce long débat qui suivit le meurtre du duc d'Orléans, marque (...) le début d'une lente évolution qui va contester, puis réduire, puis ruiner la place du serment dans la vie politique» (pp. 422-423).

Fica deste livro a lição de um verdadeiro clerc, jubilado da Função Pública mas continuadamente prodigalizando os frutos do seu múltiplo saber; com grande júbilo dos seus fiéis leitores.

Entre 2002 e 2008 BG publicou ainda mais 3 livros.

Do primeiro dos anos em causa data Opinion (L') publique à la fin du Moyen Âge, d'après la Chronique de Charles VI du Religieux de Saint-Denis ${ }^{42}$.

$\mathrm{Na}$ «Introduction» (pp. 7-17), e num contexto de prisão de João II o Bom em Inglaterra e de afirmação do futuro Carlos V (finais de 1357), a dilucidação de dois-conceitoschave:

- «Propaganda»: Vocábulo post-medieval, com origens, na viragem de Quinhentos para Seiscentos, na Congregatio de propaganda fide. O deslizar de um significado religioso e institucional para o de formas de difusão de ideias é, no essencial, um legado da Revolução Francesa, e desde Oitocentos que o termo

\footnotetext{
${ }^{\star * \star}$ Esta secção final é inédita, elaborada após a morte de BG.

${ }^{42}$ GUENÉE, 2002.
} 
tende a designar «l'action exercée sur l'opinion pour l'amener à avoir certaines idées politiques et sociales» (p. 8).

- «Opinião»: Termo bem medieval e moderno, significando «un avis, un jugement, un sentiment, une croyance qu'une personne peut avoir» (pp. 8-9). Após um breve percurso pelas definições de Seiscentos e Setecentos, BG recua para a realidade das ideias em finais da Idade Média, concluindo aí que «dans ce domaine comme dans tant d'autres, les réalités ont largement devancé les mots. On peut parler de propagande et d'opinion publique au XIV siècle» (p. 10).

Fazem sequência oito capítulos, onde sucessivamente se tem em conta sentimentos e atitudes (amor e alegria, descontentamento e ódio), a comunidade francesa, estruturas sociais e grupos de opinião, afirmação de duas élites («les gens d'autorité» e «les sages»), a intervenção do historiador e opinião pública e propaganda no decénio 14011411.

Em 2004 é a vez de Folie (La) de Charles VI, Roi Bien-Aimé ${ }^{43}$, obra sintetizante / finalizante de muito do que BG até então escrevera ${ }^{44}$. Sete capítulos e um epílogo são contidos pelo volume; e neles sucessivamente se analisam o vocabulário da doença régia, testemunhos e realidades da mesma, opiniões sábias e vulgares, os limites da Medicina, a «surdez de Deus» face às preces, a noção de «rei inútil», e a realeza e o reino face à loucura de um rei. Em epílogo, o porquê de um cognome, «Le Bien-Aimé».

Em 2008, por último, BG dá à estampa Du Guesclin et Froissart. La fabrication de la renommée ${ }^{45}$. Três partes sucessivas («Les mots», «Renommée et sociéte»e «La renommée de l'historien») desdobram-se num total de 12 capítulos, versando estes o vocabulário do renome e da glória, o renome face ao nascimento, ao mérito, à

\footnotetext{
${ }^{43}$ GUENÉE, 2004.

${ }^{44}$ Particularmente os reunidos em GUENÉE, 1999, já atrás referidos.

${ }^{45}$ GUENÉE, 2008.
} 
celebridade e à memória, o renome de Bertrand du Guesclin, historiadores anónimos, com nome e com renome (séculos XII-XIV) e o renome de Jean Froissart.

Uma coisa terá necessariamente impressionado quem minimamente haja conhecido Bernard Guenée: o seu inconfundível sentido de humor, manifestando-se tanto a meio da mais informal das conversas, como em qualquer circunspecto momento de uma palestra ou comunicação. Poderia abonar o que disse com a narração de uns tantos episódios que presenciei; mas fico-me, naturalmente, por um.

Foi em Maio de 1996. Ao abrir, na mairie de Saint-Denis, o Colóquio internacional em sua homenagem ${ }^{46}$, cerca de um ano decorrido sobre a jubilação, Bernard Guenée, falando, na circunstância, sobre Liturgia e $\operatorname{poder}^{47}$, começou por salientar o carácter algo bizarro da situação: ele, o homenageado, tinha também que intervir com uma comunicação. Isto, prosseguiu, fazia-lhe lembrar uma velha anedota suíça. Num passado já remoto, um forasteiro chega a uma pequena cidade do País em causa. É domingo, ao fím da manhã, e já terminou a missa do dia. Na praça principal da urbe ergue-se a mairie, que inclui residência de função para o maire. A varanda da zona residencial da mairie tem as portadas abertas; mas ninguém se lá encontra; ao mesmo tempo que, cá em baixo, uma banda (orchestre, na circunstância) executa uma peça, sendo que os músicos parecem olhar frequente e jubilosamente para a dita varanda. O forasteiro acha que há ali algo de inusitado. E procura esclarecer-se, interrogando alguém claramente da

46 AUTRAND, Françoise; GAUVARD, Claude; MOEGLIN, Jean-Marie (Éd.) - Saint-Denis et la royauté. Études offertes á Bernard Guenée, membre de l'Institut, Paris Publications de la Sorbonne, 1999, comunicação de BG: «Liturgie et politique. Les processions spéciales à Paris sous Charles VI»: 23-49; reed. em GUENÉE, 1999: 425-454.

${ }^{47} \mathrm{~V}$. nota anterior. 
terra, presenciando a cena por ali perto. [E reproduzo o diálogo em língua francesa, para evitar qualquer perda de sabor do mesmo]:

- Qu'est-ce qui se passe?

- C'est l'orchestre qui joue en l'honneur du maire.

- Mais le maire n'est pas là !...

- C'est qu'il joue dans l'orchestre...

\section{Principais obras de Bernard Guenée:}

GUENÉE, 1963 - Tribunaux et gens de justice dans de bailliage de Senlis à la fin du Moyen Âge (vers 1380-vers 1550), Estrasburgo, Publications de la Faculté des Lettres.

GUENÉE, $1968^{48}$ - Entrées (Les) royales françaises de 1328 à 1515, Paris, CNRS.

GUENÉE, 1971 - Occident (L') aux XIV et XVe siècles. Les États, Paris, PUF $\left({ }^{6}, 1998\right)$.

GUENÉE, 1977 (Dir.) - Métier (Le) d'historien au Moyen Âge, Paris.

GUENÉE, 1980 - Histoire et culture historique dans l'Occident médiéval, Paris, Aubier-Montaigne $\left.{ }^{2}, 1991\right)$.

GUENÉE, 1981 - Politique et histoire au moyen Âge. Recueil d'articles sur l'histoire politique et l'historiographie médiévales (1956-1981), Paris, Publications de la Sorbonne.

GUENÉE, 1987 - Entre l'Église et l'État. Quatre vies de prélats français à la fin du Moyen Âge (XIII ${ }^{\mathrm{e}}-\mathrm{XV}^{\mathrm{e}}$ siècle), Paris, Gallimard.

\footnotetext{
${ }^{48}$ Em col. c/ Françoise LEHOUX.
} 
GUENÉE, 1992 - Un meurtre, une sociéte. L'assassinat du duc d'Orléans, 23 novembre 1407, Paris, Gallimard.

GUENÉE, 1999 - Un roi et son historien, Vingt études sur le régne de Charles VI et la Chronique du Religieux de Saint-Denis, Paris, Diff. De Boccard («Mémoires de l'Académie des Inscriptions et Belles-Lettres», nouvelle série, t. XVIII).

GUENÉE, 2002 - Opinion (L') publique à la fin du Moyen Âge, d'après la Chronique de Charles VI du Religieux de Sant-Denis, Paris, Perrin.

GUENÉE, 2004 - Folie (La) de Charles VI, Roi Bien-Aimé, Paris Perrin.

GUENÉE, 2008 - Du Guesclin et Froissart. La fabrication de la renommée, Paris, Tallandier.

\section{COMO CITAR ESTE ARTIGO}

\section{Referência electrónica:}

HOMEM, Armando Luís de Carvalho - "Bernard Guenée (1927-2010)”. Medievalista [Em linha]. Nº11, (Janeiro de 2012). [Consultado dd.mm.aaaa]. Disponível em http://www2.fcsh.unl.pt/iem/medievalista/MEDIEVALISTA11 Vhomem1102.html. ISSN 1646-740X.

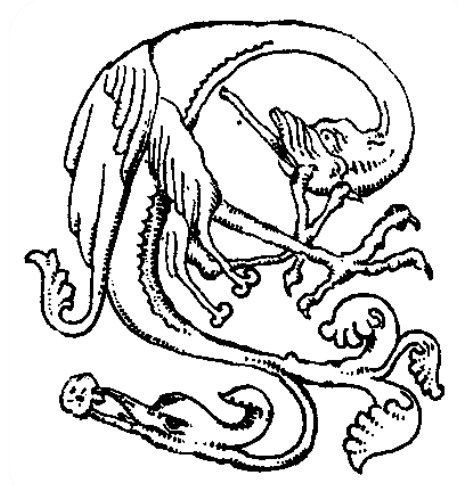

